\title{
Analysis on the Influence of Shaft and Cross Passage Turn to the Main Line of Ingate under Different Construction Schemes
}

\author{
Zhanping Song $\mathbb{D}^{1,2}$ Qi Liu $\mathbb{D}^{1,}{ }^{1}$ Yuwei Zhang $\mathbb{D}^{1,2}$ Xiaoxu Tian $\mathbb{D}^{1,2}$ and Guannan Zhou ${ }^{3}$ \\ ${ }^{1}$ College of Civil Engineering, Xi'an University of Architecture and Technology, Xi'an 710055, China \\ ${ }^{2}$ Shaanxi Key Laboratory of Geotechnical and Underground Space Engineering, Xi'an, Shaanxi 710055, China \\ ${ }^{3}$ China Railway Construction Bridge Engineering Bureau Group Co., Ltd., Tianjin 300300, China
}

Correspondence should be addressed to Zhanping Song; songzhpyt@xauat.edu.cn

Received 6 October 2020; Accepted 6 January 2021; Published 29 January 2021

Academic Editor: Xingzhou Chen

Copyright $\odot 2021$ Zhanping Song et al. This is an open access article distributed under the Creative Commons Attribution License, which permits unrestricted use, distribution, and reproduction in any medium, provided the original work is properly cited.

In the weak stratum, the construction of ingate is a key technical problem at the place where the shaft and cross passage turn to the tunnel. Based on Lanzhou Metro, the corresponding changes to the construction plan of the ingate of the section tunnel were made. Finite element software is used to carry out three-dimensional modeling and design of subway shaft, cross passage, and tunnel structures in connected sections. The influence of the two construction schemes on surface settlement, deformation, and stress of tunnel support structure and stress conversion of ingate are compared, as well as the fitting degree between numerical simulation results and field monitoring data. Finally, the optimal scheme and key points of construction control are determined. The results show that the optimization scheme has obvious advantages in the control of surface settlement and the deformation of shaft and cross passage support. However, the difference between the stress and deformation of the tunnel supporting structure and the original plan is not obvious. Since the project focuses on shaft, cross passage, and tunnel connection section, the changed construction scheme is better.

\section{Introduction}

In recent years, urbanization has been accelerated, surface routes have been interleaved, and various large-scale buildings have risen. The subway, as a type of urban rail transit, plays an increasingly important role in urban public transportation, bringing new development opportunities to underground space engineering including tunnel construction. Meanwhile, it has also put forward more research topics and technical challenges.

In the urban underground engineering construction with dense existing buildings (structures), the method of excavation or cover excavation, which has little impact on traffic, is widely used [1-9]. Among them, ingate, as the transition section connecting shaft, cross passage, and section tunnel, has complex construction technology, great disturbance to surrounding strata, and accompanied by structural stress conversion, which is the key and difficult point of subway tunnel construction [10-13]. During the excavation process of the ingate, the structure and mechanical properties of the rock mass will change due to engineering behavior, thereby disturbing the original stress field [14]. A few improper measures can easily lead to a series of engineering accidents. In view of the stability of ingate in the subway tunnel, Guo [15] systematically summarized the comprehensive construction technical measures to reduce the risk of ingate by analyzing the influence of engineering geological and surrounding environment, construction shaft location, and other factors on the construction risk of ingate in the Beijing metro tunnel. Bai and Ji [16] discussed the control effect of different reinforcement measures on the formation deformation in the construction of ingate and proposed an effective way to control the horizontal convergence in the ingate tunnel, that is, the rapid closure of the cross passage. Song et al. [17] studied the influence of the magnitude and direction of the principal stress on the deformation law of the roof, floor, and surrounding rock of ingate and the distribution characteristics of the maximum principal stress area by means of rock 
mechanics experiment, theoretical analysis, and numerical simulation. Jiang et al. [18] concluded that ingate is the weak link of the whole tunnel structure by studying the ingate project of the Shenzhen metro tunnel. According to different types of surrounding rock, Zhan Ping Song et al. [19] proposed two construction schemes of "shaft followed by cross passage construction" and "cross passage parallel shaft construction" to influence the deformation of shaft support and the stress transformation of ingate under five different levels of surrounding rock. Taking Zhangshi highspeed double arch tunnel project as the background, Mao et al. [20] compared the influence of different construction schemes on the overall structure and support of the tunnel by means of field monitoring and numerical simulation and optimized the original design scheme. Liao et al. [21] studied the demolition and excavation scheme of ingate in shaft, and based on the stratum data and engineering design data obtained from surface survey, made a comparative analysis of FLAC3D software for the two supporting schemes when ingate was demolished. Han [22] analyzed and judged the settlement monitoring data and verified that the stress conversion system and advanced support and reinforcement technology of ingate support frame structure are reasonable and reliable in ensuring the safety of the structure itself and surrounding structures.

The research conducted by the above scholars has positive guiding significance for the deformation control of the ingate transition section of the subway shaft. However, in terms of structural forces and deformations, there are still limitations to the study of special spatial forms where shafts, cross passages, and tunnel main lines intersect each other. In this paper, the background of the project was the construction of shaft and cross passage turn to the main line of the section tunnel, in the Paihong South Road parking lot section of Lanzhou Metro Line 2. Through numerical simulation method, the difference of stress and deformation of ingate under two different construction schemes was analyzed. Based on the analysis results, the optimal construction scheme was selected. This paper can provide a reference for the design and construction of shaft and cross passage turn to the section tunnel in subway engineering.

\section{Engineering and Geological Overview}

The Paihong South Road parking lot and the fifth bus company station are, respectively, located at the east and west ends of the entrance and exit line of the parking lot. Design mileage of the section tunnel is as follows: $\mathrm{RK} 0+024.30 \sim \mathrm{RK} 0+300.00$ is a double arch section with a total length of $275.7 \mathrm{~m}$. The layout is shown in Figure 1. The strata along the project are mainly quaternary holocene alluvial and proluvial $\left(Q_{4}^{a l}\right)$ loess-like soil, quaternary $\left(Q_{4}^{\mathrm{ml} l}\right)$ artificial fill, sandy pebble, and lower tertiary oligocene $\left(E_{3}\right)$ siltstone. In addition, according to the soil property, wave velocity test results, and water level buried depth, the surrounding rock can be comprehensively determined as grade VI. The geological vertical section is shown in Figure 2.

\section{Construction Scheme}

In order to ensure the safe and effective implementation of the project, the construction organization plan and construction process should strictly follow the basic principle of first protection and then excavation. 15 days before the tunnel is excavated, well point precipitation measures must be adopted for the tunnel area. The depth of precipitation should be 1 meter below the structural floor to keep the tunnel under no water.

3.1. Construction Scheme of Shaft Turn to Cross Passage. The construction of the intersection of the shaft and the cross passage adopts the construction scheme of "shaft followed by cross passage construction." The shaft excavation will be carried out after the completion of surrounding dewatering. Figure 3 shows the construction process of "shaft followed by cross passage construction." The key points of construction technology are as follows:

(1) Shaft section construction: Excavate the lock section and set the shaft wall support in the lock section. The standard section of shaft adopts C25 concrete spraying and grid steel frame to form the shaft wall support structure.

(2) Construction of shaft bottom section: The shaft bottom is constructed to the position $3.0 \mathrm{~m}$ below the bottom elevation of cross passage. C30 concrete is used for bottom sealing.

(3) Construction of ingate of cross passage: (1) After the bottom seal of the shaft is completed, take the construction platform to the height of the upper step of the cross passage to break the upper step of the cross passage. (2) After the ingate breaking operation is completed, the steel grid support should be densely arranged. The shotcrete should be used to close the excavation face and set up temporary inverted arch. (3) After stepping on the cross passage for $3 \mathrm{~m}$, the concrete in the middle of the ingate should be broken away and the steel grid should be installed. Shotcrete is used as the initial support of the cross passage and a temporary arch is set. (4) The construction steps of lower steps are the same as those of upper and middle steps. The structure and supporting parameters of shaft and cross passage are shown in Figure 4.

3.2. Design and Construction Scheme of Shaft and Cross Channel Tunnel. In order to exert the three-dimensional supporting effect of the palm face, the core soil part is retained during the upper half-section construction to maintain the stability of the palm face. The key points of construction technology are as follows:

(1) Before the ingate of the section tunnel is broken, the combination of large pipe shed and advanced small pipe grouting is used to prestrengthen the stratum. The supporting parameters are shown in Figure 4. The vertical spacing of the grid steel frame within $3 \mathrm{~m}$ 


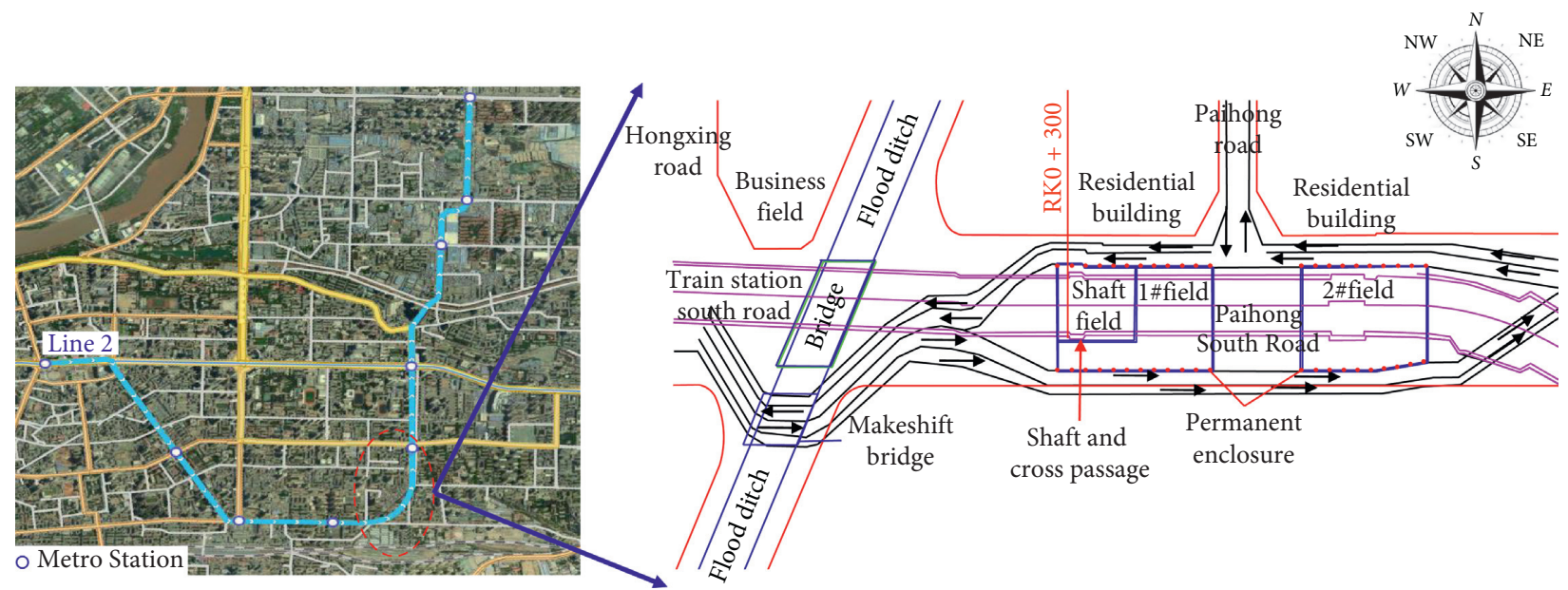

FIgURE 1: Plane layout of access line marks.

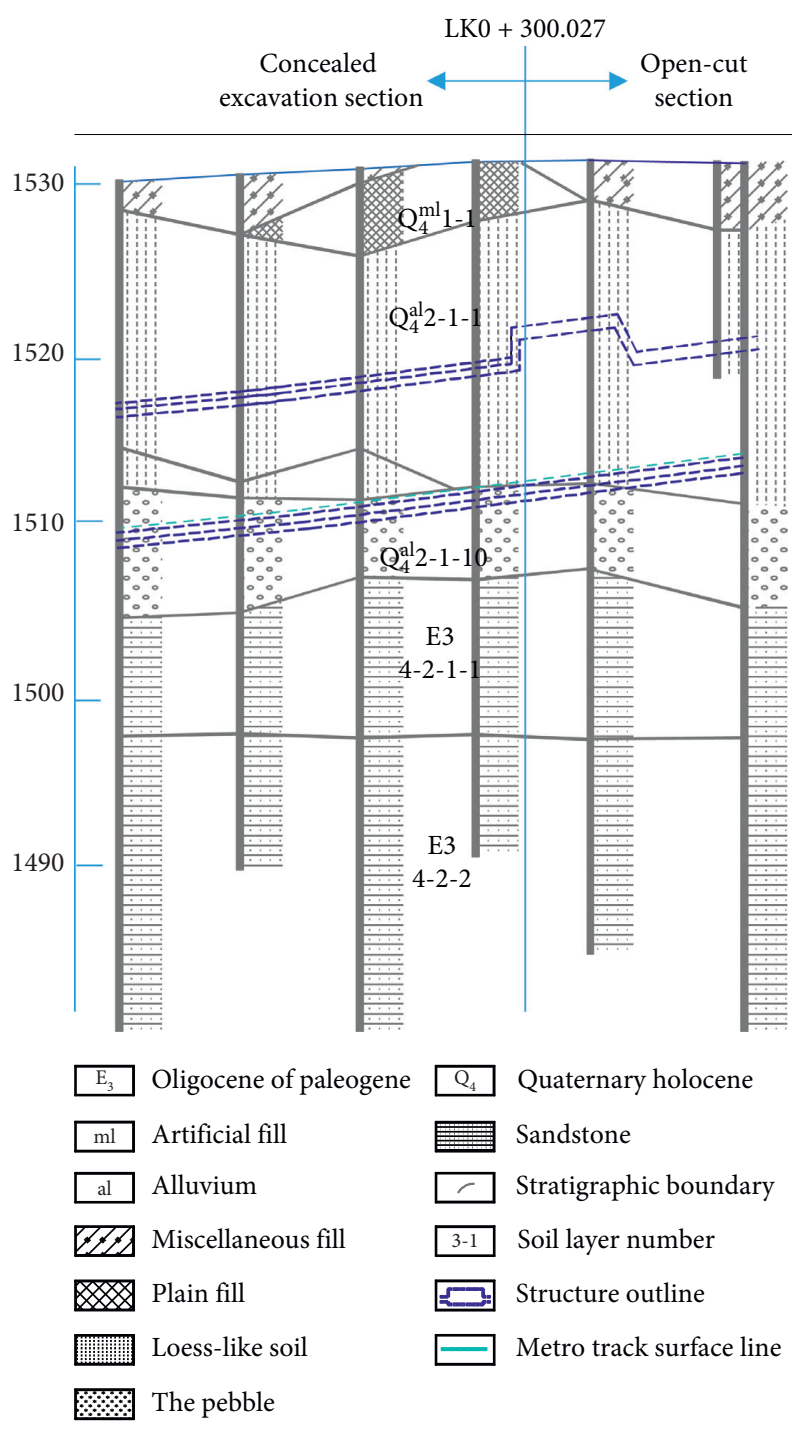

FIgURE 2: Geological longitudinal profile of the access line of Paihong South Road parking lot.

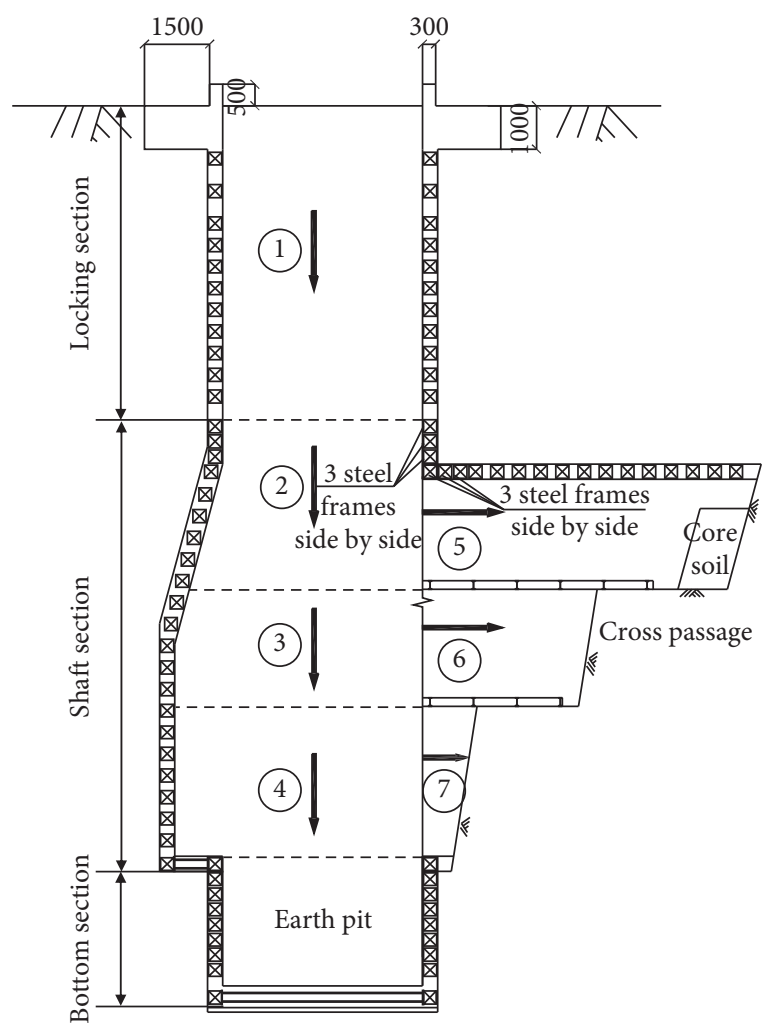

FIgURE 3: Construction sequence diagram of ingate with shaft and cross passage (unit: $\mathrm{mm}$ ).

of the ground is $0.75 \mathrm{~m}$, and the spacing below $3 \mathrm{~m}$ is $0.5 \mathrm{~m}$. The expansion section and the soil pit are $0.35 \mathrm{~m}$. After the tunnel is constructed to the standard section, the circular spacing of the advance small conduit is changed from $0.30 \mathrm{~m}$ to $0.40 \mathrm{~m}$.

(2) The each excavation footage of the tunnel bench should not be too long, and $3 \sim 5 \mathrm{~m}$ is appropriate. After the excavation of the middle drift for $20 \mathrm{~m}$, the 

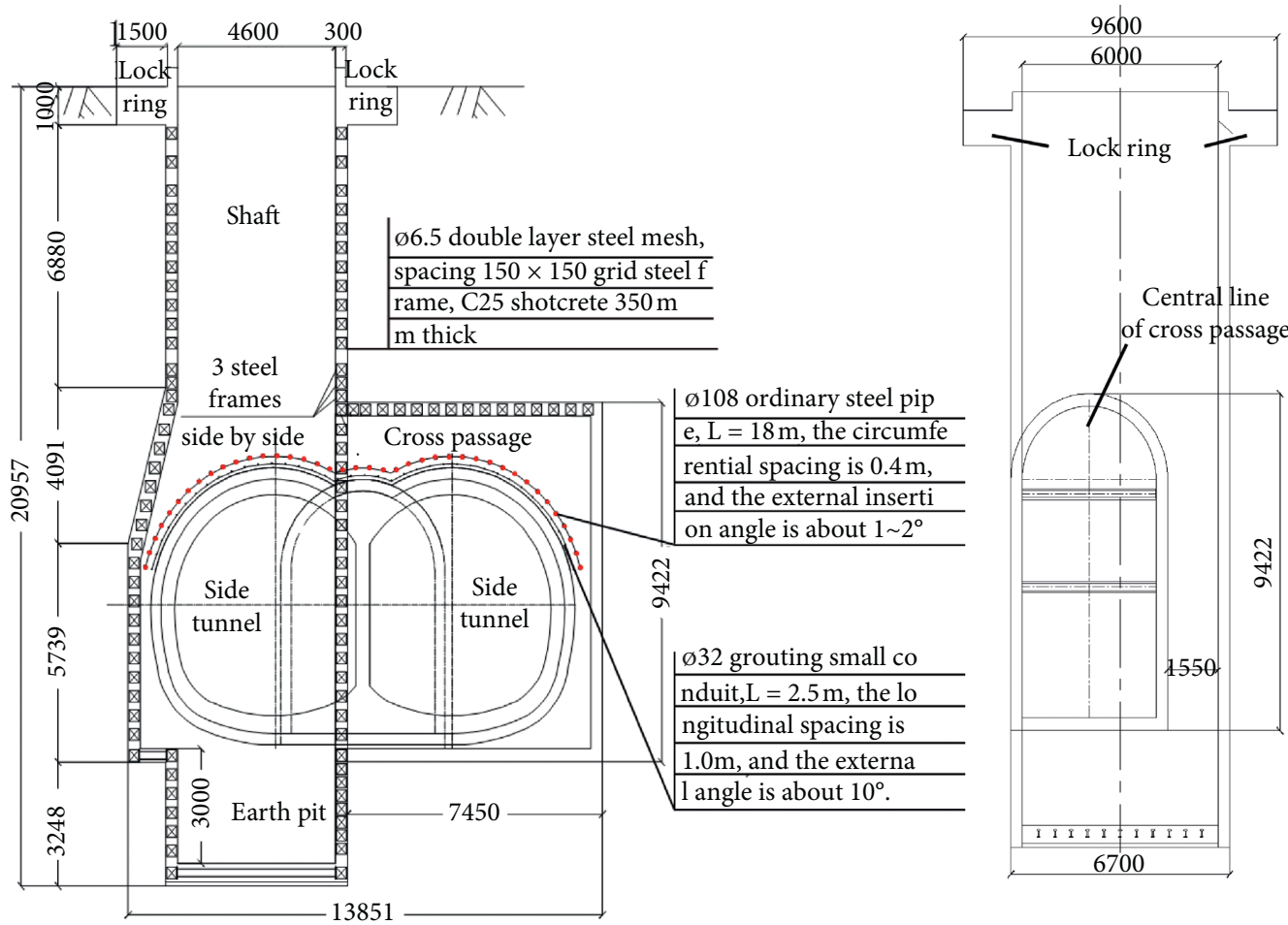

Figure 4: Design drawing of shaft and transverse passage to the section tunnel (unit: $\mathrm{mm}$ ).

lining construction of the partition wall should be started and temporary supports should be set to prevent the displacement of the partition wall. The middle drift continues to be excavated, and at the same time, the construction of the side tunnel is started.

Due to the close proximity of the cross passage to the west side, the steel frame of the guide tunnel in the area of the shaft cannot form a ring during the construction of the guide tunnel on the east side of the cross passage. The treatment method of using the steel frame of the supporting middle drift on the south side of the cross passage to make the north side tunnel can form a loop normally.

The specific construction steps are as follows. (1) A large pipe shed is placed at the entrance of the tunnel. (2) The shaft and cross passage support on the upper step area of the middle drift are broken, and the advanced small pipe grouting of the middle drift vault is carried out. Then, excavate the guide tunnel to the upper step and provide initial support and temporary support for the upper step. (3) The shaft and cross passage support on the lower step area of the middle drift are broken. Then, excavate the lower steps of the middle drift and construct the initial support and inverted arch. (4) Construct the middle partition wall lining and temporary support of the middle partition wall. Later, the shaft and cross passage support within the scope of the left and right sides of the tunnel are broken, and the advanced small pipe grouting for the vault of the left and right sides of the tunnel is carried out. Afterwards, the upper step of the left and right sides of the tunnel is excavated at a staggered distance of $5 \mathrm{~m}$ and is initially supported (the ingate section is side by side with 3 steel frames to improve the safety reserve of the weak section). Finally, set up temporary arch support. (5) Break the cross passage support of the shaft within the scope of the lower steps of the left and right side tunnels. Then, excavate the lower steps of the left and right side tunnels and construct the initial support and inverted arch. (6) After the convergence in the tunnel tends to be stable, construct the secondary lining and break the temporary support in the tunnel. See Figure 5 for the construction sequence of the section concealed excavation tunnel.

\subsection{Optimization Scheme of Shaft and Cross Passage Turn to} Section Tunnel. It is the most important two indexes to keep the stability of the tunnel structure and control the deformation of the stratum in the excavation of the subway tunnel [23]. Because the space position of the shaft and the left line tunnel overlaps, using the original construction scheme to break the ingate may cause the large deformation of the stratum and other results. Therefore, the optimization scheme makes corresponding scheme changes to the first $20 \mathrm{~m}$ of the tunnel main line. In addition, in the following other areas, the middle drift scheme designed in the early stage is still used for construction. The RK0+300 section and the supporting structure of the shaft and cross passage are used as the main control parts to compare and analyze the stress and deformation of the structure.

The specific construction scheme is as follows, (1) Break the support within the scope of cross passage and reserve 

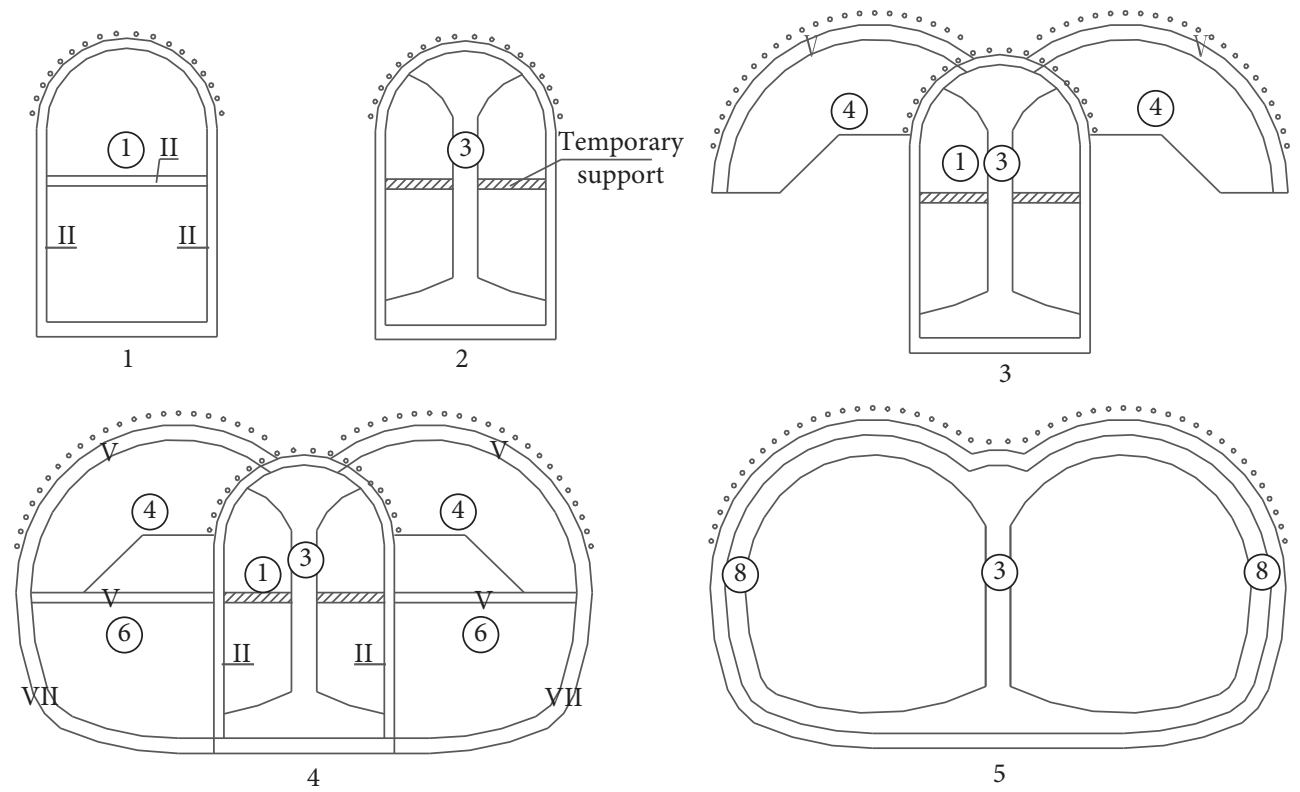

Figure 5: Step diagram of section tunnel construction.

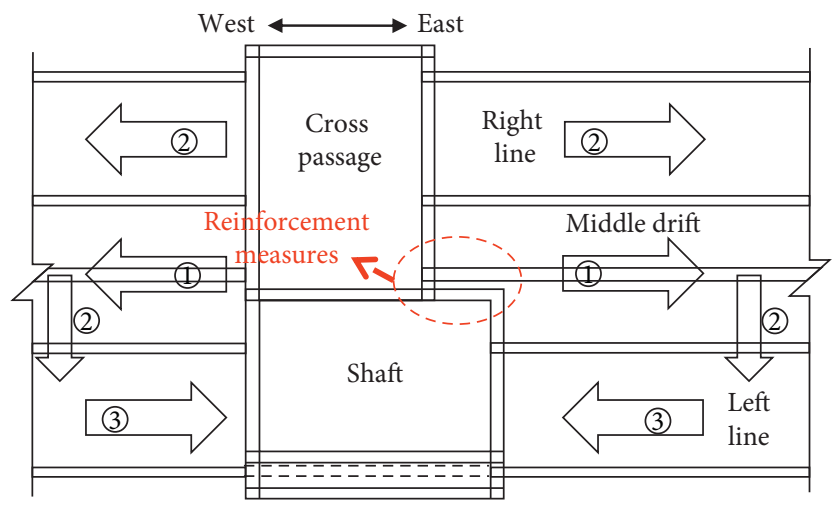

Figure 6: Plane position and construction diagram of shaft cross passage and section tunnel.

the support within the scope of shaft. (2) The construction of the middle drift is the same as the original design construction scheme. (3) After the excavation of the middle drift for $20 \mathrm{~m}$, start the lining construction of the middle partition wall and set up temporary support to prevent the displacement of the middle partition wall. At the same time, carry out the side tunnel construction. (4) The construction of the side tunnel of the right line is the same as the original design scheme. After the palm face of the middle drift is closed, the left side of the tunnel raises the cross section and constructs to the direction of the shaft. The construction distance between the upper and lower steps is changed from $5 \mathrm{~m}$ to $3 \mathrm{~m}$ until the construction reaches the shaft. (5) With the adjustment of excavation steps, the pre-reinforcement of the left line vault is also carried out from the tunnel face of the middle drift to the direction of the shaft. At the same time, the rear face of the left line tunnel is closed to maintain stability. The initial support in the left line tunnel and the construction tunnel is excavated. When the construction reaches the position of the shaft, the grid steel frame is densely arranged. In addition, the construction steps are the same as the original design. The construction schematic diagram of the optimization scheme is shown in Figure 6.

In the space intersection section with complex structural stress transformation, the construction has great mutual influence and high risk, so it is particularly important to optimize the construction scheme. Because the original design destroyed the east and west side of the shaft wall, it has no stable point of force and lost the role of support. Compared with the original design scheme, the optimization scheme takes into account the situation of opening the ingate on three sides of the shaft and chooses to change the construction sequence of the left line tunnel to realize the construction conversion of the ingate section. This will improve the structural stability during construction and reduce construction risks. Based on the characteristics of various construction procedures of the optimization scheme, construction monitoring should be strengthened for key parts of the ingate section. 


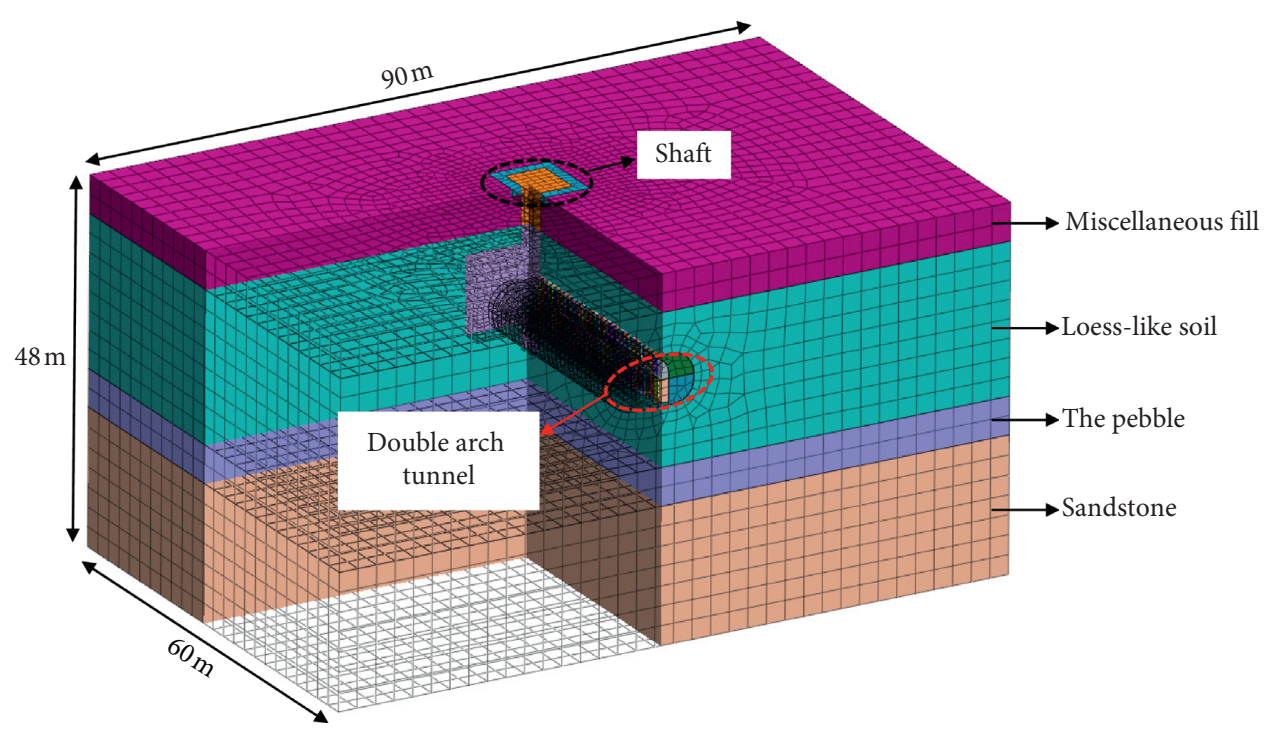

FIgURE 7: Numerical simulation calculation model and grid division.

\section{Numerical Model Simulation}

According to the engineering geological data and the natural environment at the scene, the predesign dimensions of the shaft and cross passage turn to the section tunnel are shown in Figure 7. The plane clearance of the shaft is $4.6 \mathrm{~m} \times 6 \mathrm{~m}$, and the depth of the shaft is $20.957 \mathrm{~m}$. The shaft, the cross passage, and the section tunnel are interconnected. The total length of the cross passage is $7.45 \mathrm{~m}$, the clear width is $4.5 \mathrm{~m}$, and the clear height is $9.42 \mathrm{~m}$. The shaft wellhead is provided with a locking ring beam with a section size of $1.5 \mathrm{~m} \times 1 \mathrm{~m}$. The section diagram of the shaft and section tunnel is shown in Figure 4.

4.1. Numerical Calculation Model. According to the engineering experience, the construction impact area is generally controlled within $3 \sim 5$ times of the construction section size. Combined with the actual geological conditions of the project, the calculated width in the horizontal direction is $90 \mathrm{~m}$. In the vertical direction, the tunnel bottom is taken down three times of the tunnel diameter and taken up to the surface. In the actual project, the bias occurs at the ingate and the buried depth of the tunnel gradually becomes shallower to the east. The entrance of ingate is the most dangerous position. The $30 \mathrm{~m}$ section of ingate entrance is taken as the model calculation length along the longitudinal direction of the tunnel.

MIDAS uses a hybrid meshing model. The tunnel and the pre-reinforced part use $1.0 \mathrm{~m}$ units, the size unit transition of $1.0 \mathrm{~m}-2.0 \mathrm{~m}$ is used for the surrounding rock near the tunnel, and the unit size of $2.0 \mathrm{~m}$ is adopted for the rest positions. The final calculation unit quantity of the model is 87648 , and the calculation model diagram and grid diagram are shown in Figure 7.

The engineering geology is complex fill and siltstone, strong weathering, broken rock mass, joint development, and poor rock mass condition. The Mohr-Coulomb failure criterion is adopted in the calculation.
In the calculation model, two-dimensional plate element is used to simulate the initial support and secondary lining, one-dimensional embedded truss element is used to simulate the advanced small pipes, and one-dimensional embedded beam element is used to simulate the stress behavior of the pipe shed. According to the geological survey data obtained from field tests and structural design data, the physical and mechanical parameters of the surrounding rock and supporting structure can be determined. At the same time, the role of the arch frame is considered by the equivalent method; that is, the elastic modulus of the steel arch frame is converted to the shotcrete. The calculation method is as follows [24]:

$$
E=E_{0}+\left(\frac{\left(S_{g} \times E_{g}\right)}{S}\right),
$$

where $E$ is the elastic modulus of the converted concrete; $E_{0}$ is the elastic modulus of the original concrete; $S_{\mathrm{g}}$ is the crosssectional area of the steel $\mathrm{arch} ; E_{\mathrm{g}}$ is the elastic modulus of the steel arch; and $S_{c}$ is the cross-sectional area of the concrete. The physical and mechanical parameters are shown in Table 1.

\subsection{Numerical Analysis Scheme}

(1) Simulation of the original design construction scheme steps: The excavation and support of shaft and cross passage section are simulated in the Midas model according to the construction steps in section 3.1. After the construction simulation of shaft and cross passage is completed, the model displacement will be reset in the next stage so as to analyze the influence of different construction schemes of the section tunnel on ingate.

The key points of the simulation of the construction steps of the tunnel in this project are as follows. (1) Break the support of the cross passage 
TABLE 1: Supporting and soil physical and mechanical parameters.

\begin{tabular}{lccccc}
\hline Material science & Elastic modulus $(\mathrm{MPa})$ & Poisson's ratio & Test weight $\left(\mathrm{kN} / \mathrm{m}^{3}\right)$ & Cohesion $(\mathrm{MPa})$ & Friction angle $\varphi\left(^{\circ}\right)$ \\
\hline Miscellaneous fill & 15 & 0.39 & 15.7 & 0.01 & 12 \\
Loess-like soil & 29 & 0.36 & 17.8 & 0.017 & 0 \\
Pebble & 250 & 0.22 & 21 & 0.03 & 20 \\
Strongly weathered siltstone & 57.5 & 0.24 & 21.2 & - & - \\
Advanced small catheter & $20 \times 10^{4}$ & 0.26 & 78.5 & - & - \\
Pipe shed & $18 \times 10^{4}$ & 0.25 & 27 & - & - \\
Primary support & $2.2 \times 10^{4}$ & 0.25 & 27 & - \\
Secondary lining & $3 \times 10^{4}$ & 0.20 & & - \\
\hline
\end{tabular}

and the shaft in the upper step range of the middle drift. Then, carry out the pre-reinforcement of the vault and the excavation and support of the upper step. (2) When the upper step footage is $5 \mathrm{~m}$, break the support of the cross passage of the shaft in the lower step range of the middle drift. Then, carry out the excavation and support of the lower step. (3) When the upper step footage is $25 \mathrm{~m}$, the support of the cross passage and the shaft within the upper step range of the left and right side tunnels should be broken. Then, the vault should be pre-reinforced and the excavation support with the upper step staggered distance of $5 \mathrm{~m}$ should be carried out. Afterwards, the lining of the middle partition wall and the temporary support of the middle partition wall should be carried out accordingly. (4) When the left and right upper steps have a footage of $5 \mathrm{~m}$, respectively, the support of the cross passage and the shaft within the scope of the lower steps of the left and right side tunnels should be broken. Then, the excavation and support of the lower steps should be carried out. (5) When the upper step has a footage of $20 \mathrm{~m}$, the secondary lining should be constructed and the temporary support in the tunnel should be broken. Figure 8 is the construction process diagram of the original design scheme.

(2) Simulation of construction steps of the optimization scheme: the construction of shaft and cross passage is the same as that of the original scheme. In the construction of the section tunnel, only the left line tunnel at the shaft side is changed. That is, before the excavation of the middle drift, only the support of the middle drift within the range of the cross passage is broken. After the excavation of the middle drift for $20 \mathrm{~m}$, the left line tunnel is returned from the palm face of the middle drift to the shaft direction until the shaft wall is broken. The construction of other parts is the same as the original design. Figure 9 is the construction process diagram of the optimization scheme.

\section{Numerical Calculation Results and Analysis}

5.1. Comparative Analysis of Deformation of Surface and Initial Support Structure. In the environment sensitive area, the settlement and deformation of the ground surface are important indexes of safety control in the subway engineering $[25,26]$. The monitoring standard sections are arranged along the tunnel centerline at an interval of $10 \mathrm{~m}$. The layout of the numerical simulation settlement monitoring points and the tunnel convergence measurement points is shown in Figure 10.

5.1.1. Comparative Analysis of Model Ground Settlement. Figure 11 shows the comparison of surface settlement curves $(\mathrm{a} \sim \mathrm{d})$ under two construction schemes at the section RK0 + 270-300. The original program simulation value and the optimization program simulation value are consistent with the deformation law, and the settlement groove appears at the center line of the tunnel.

On the whole, the deformation trend of numerical simulation results is basically the same, and the optimization scheme is more gentle and regular than the original scheme. After the construction deformation is stable, the maximum value of the original design scheme is $13.82 \mathrm{~mm}$, and the optimization scheme is $13.43 \mathrm{~mm}$, which appears at $\mathrm{RK} 0+270$. The results of numerical simulation in the $\mathrm{RK} 0+270-290$ section are basically the same as the original scheme. The deformation of the two schemes is different only at the position of RK0 +300 shaft, and the peak range is about $1.7 \mathrm{~mm}$. In general, the optimization scheme is better than the original scheme and the numerical simulation results are more reliable. The maximum settlement value is less than the warning value of surface settlement in the large section of the mining method in the design document by $40.0 \mathrm{~mm}$, which meets the construction control requirements.

Based on the comparison results of numerical simulation, the conclusion of numerical simulation of the optimization scheme adopted in the double arch tunnel section of the access line section is reliable. It can ensure the safe construction of the project.

5.1.2. Comparative Analysis of Model Vault Settlement. In order to analyze the settlement change of the tunnel vault position after construction, the vault settlement value is extracted along the tunnel axis direction. According to the results of numerical analysis, the settlement of tunnel vault is the largest at the sections of RK $0+270$ and RK0 +280 . The monitoring section on the model boundary may be affected by the boundary conditions. Therefore, the section 

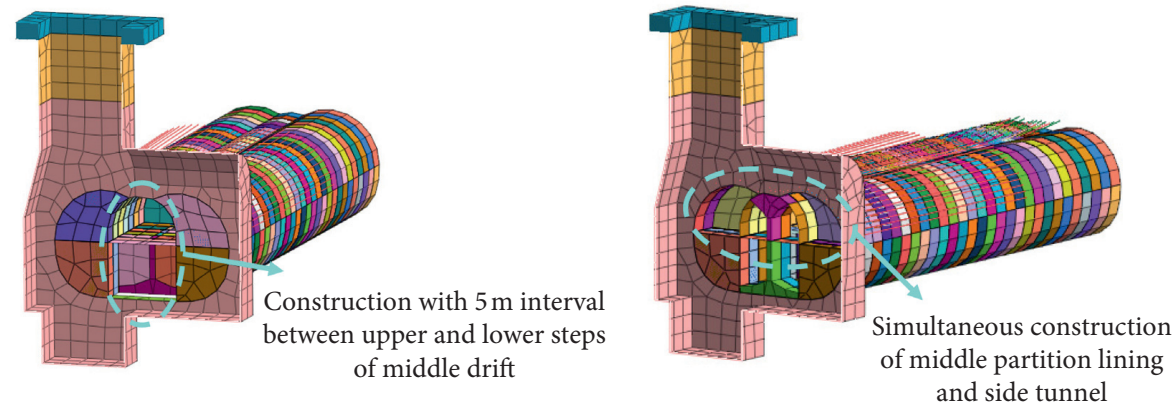

FIGURE 8: Construction procedure of the original design and construction scheme.
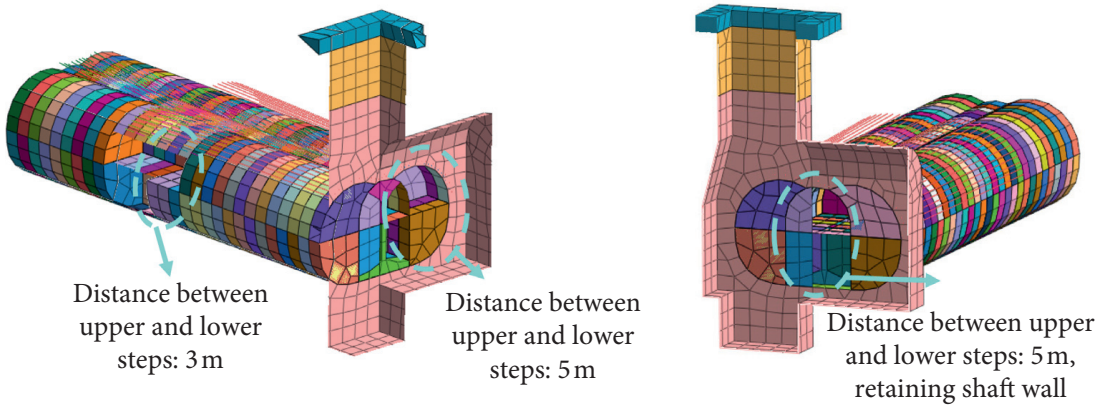

FIGURE 9: Construction procedure of the optimization scheme.

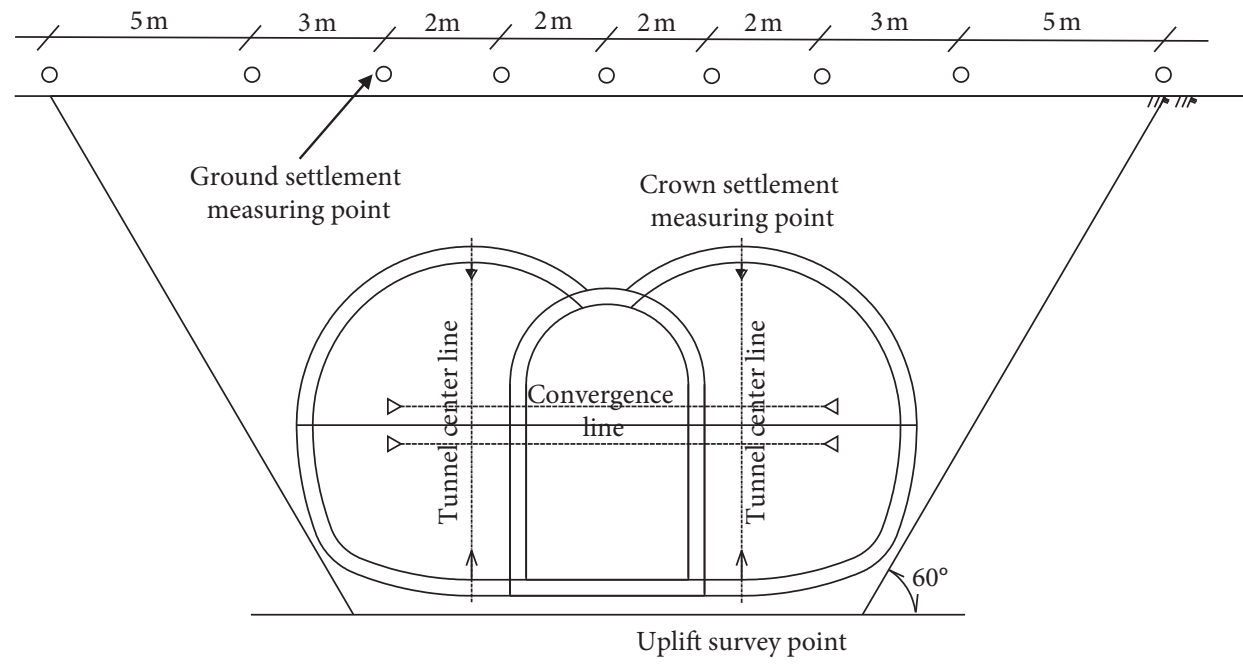

FIGURE 10: Section layout of underground excavation monitoring points.

$\mathrm{RK} 0+280$ is selected to analyze the vertical deformation law of the tunnel vault in each stage. In addition, the section $\mathrm{RK} 0+300$ is the key part of the ingate section, which is also selected for analysis.

Figures 12 and 13 are the comparison curves of the settlement and deformation of the tunnel vault at various stages at the cross section $\mathrm{RK} 0+280$ and 300 . Under the two schemes, the deformation rule of the right tunnel arch is consistent and the difference of the left tunnel is large, which is mainly caused by the change of the left line scheme. It can be seen from the curve of the settlement of the vault after construction that the maximum settlement of the model occurs at the RK0 +280 vault, and the left and right tunnels are about $21 \mathrm{~mm}$. The stability value of the optimized scheme is basically the same as the original scheme. The warning value of the deformation in the tunnel specified in the design document is $30 \mathrm{~mm}$, so it meets the construction control requirements. Based on the above analysis, the $\mathrm{RK} 0+280$ left tunnel arch is further taken as a typical section. When the palm face of the steps on the left and right tunnels is about $6.0 \mathrm{~m}$ away from the monitoring section, the monitoring point produces vertical displacement. When the palm face passes the monitoring surface about $12 \mathrm{~m}$, the deformation of the tunnel arch will tend to stabilize. In the optimization 


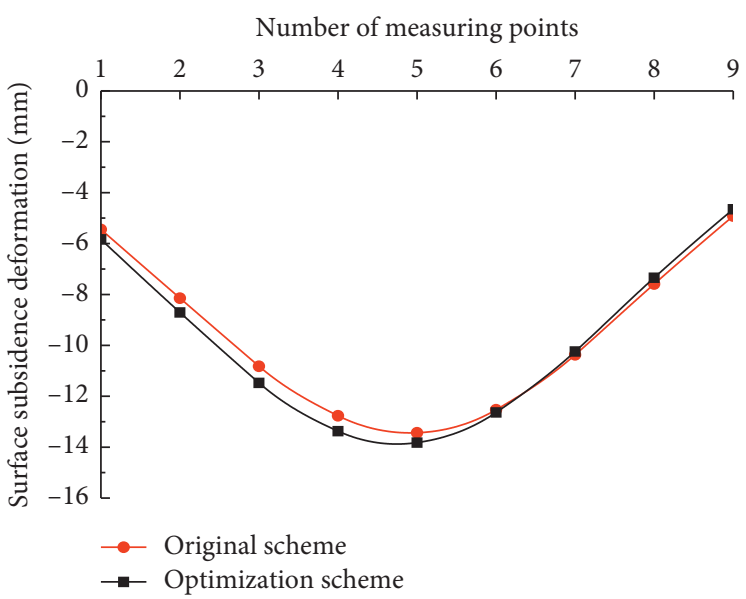

(a)

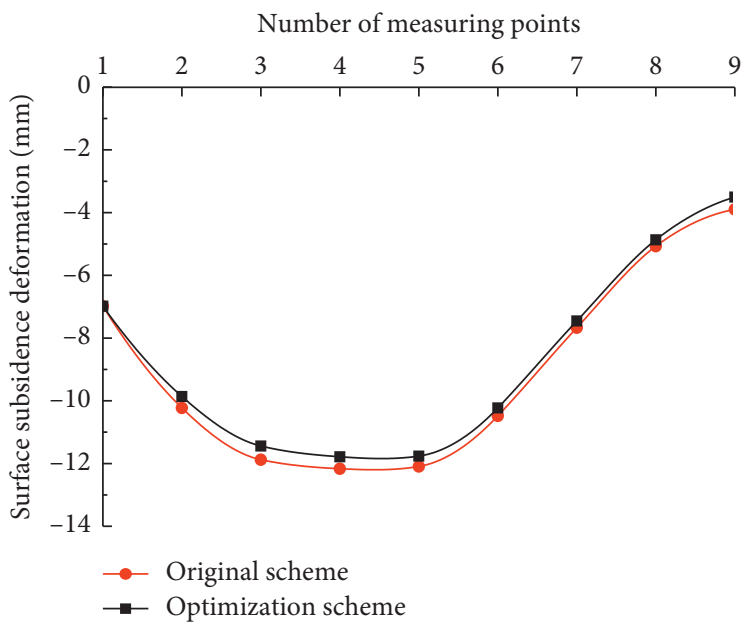

(c)

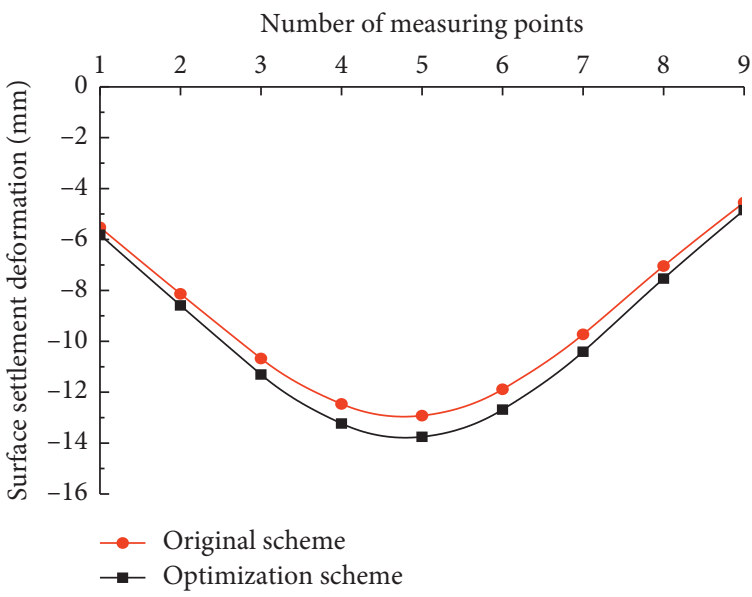

(b) Number of measuring points

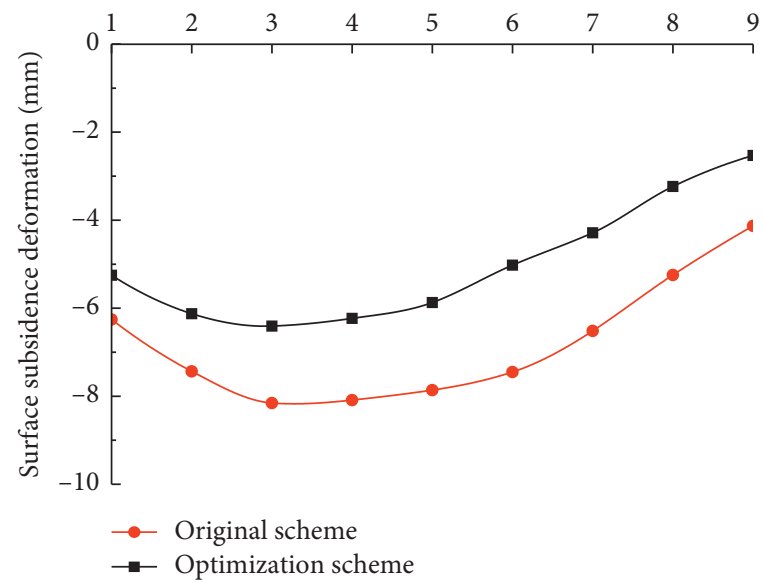

(d)

FIGURE 11: Comparative analysis of surface subsidence: (a) RK0 + 270; (b) RK0 + 280; (c) RK0 + 290; (d) RK0 + 300 .

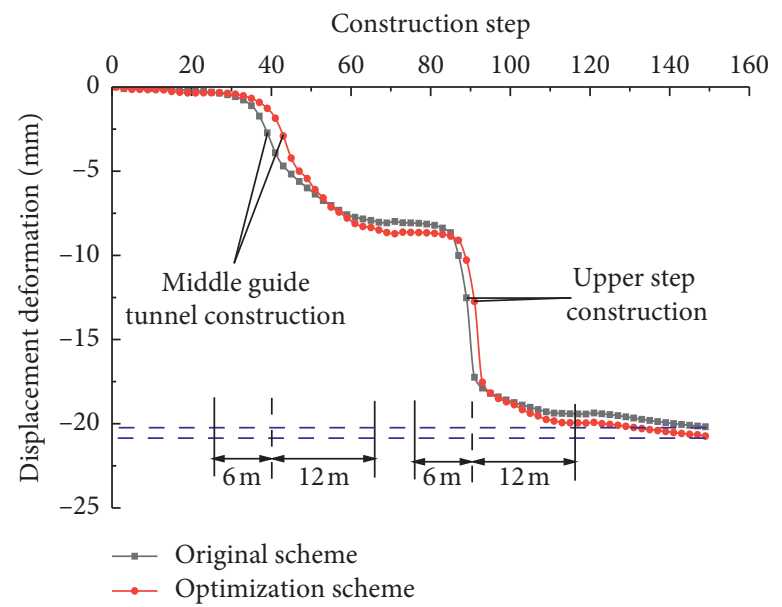

(a)

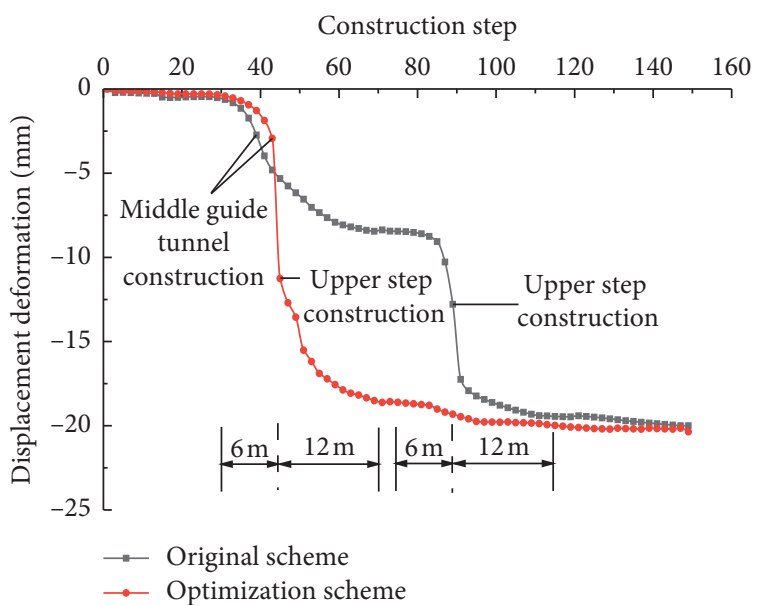

(b)

FIGURE 12: Comparison and analysis of arch deformation at RK0 + 280: (a) right tunnel vault and (b) left tunnel vault. 


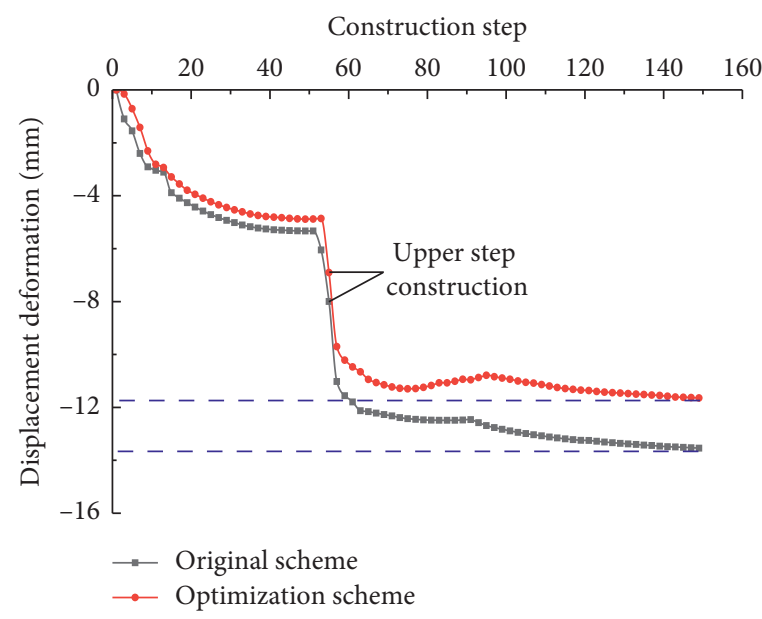

(a)

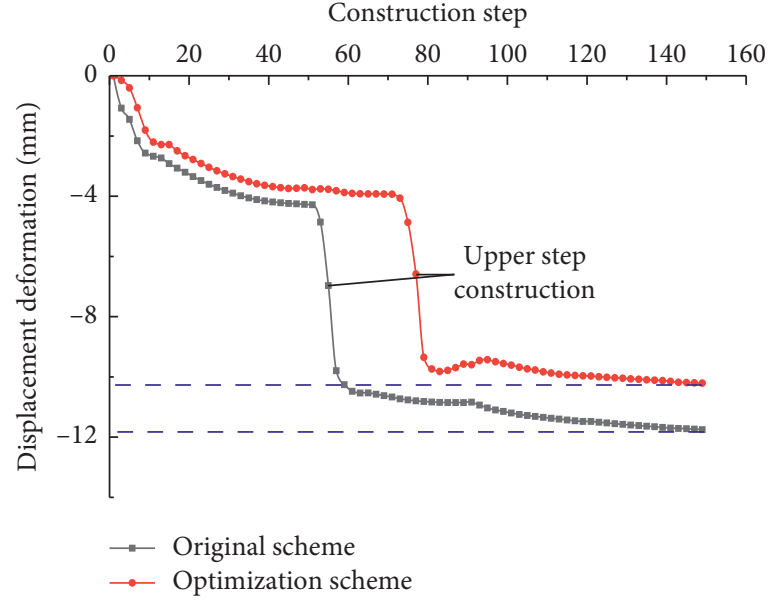

(b)

FIGURE 13: Comparative analysis of arch roof deformation at RK0 + 300: (a) right tunnel vault and (b) left tunnel vault.

plan, the middle drift and the left tunnel at RK0 +280 are constructed continuously. Therefore, a one-time sudden increase in the settlement of the arch of the left tunnel is about $20 \mathrm{~m}$. In the original scheme, the settlement caused by the construction of the left tunnel at RK0 +280 is slightly larger than the settlement of the vault caused by the construction of the middle drift. And, each is about $1 / 2$ of the total settlement.

According to the above analysis, at the location of $\mathrm{RK} 0+280$, the affected range of the left and right tunnel vault settlement is about $1 \mathrm{D}$ behind the palm face and 1/ $2 \mathrm{D}$ in front of the palm face ( $\mathrm{D}$ is the horizontal diameter of the tunnel). The sinking of the tunnel arch is greatly affected by the construction of the middle guide tunnel, but the main impact comes from the construction of the tunnel.

\subsubsection{Comparative Analysis of Convergence in Tunnel.} Figure 14 is a comparison curve of the lateral convergence of the tunnel supporting structure of the RK0 280 section under different construction schemes. According to the comparison and analysis of displacement and deformation of each stage in the figure, the following can be seen:

(1) In the stage of tunnel upper step excavation, the arch shoulder and arch waist are obviously compressed. In the stage of lower step excavation, the arch shoulder is expanded and the arch waist and arch foot are obviously compressed (for the left tunnel, the positive value represents tunnel compression, the negative value represents expansion, and the right tunnel is opposite to the left tunnel).

(2) Through the analysis of the construction steps $0-40$ of the two construction schemes, the construction of the middle drift caused the expansion and deformation of the left and right tunnel arch shoulders and arch sills and the compression deformation of the right tunnel arch foot. And, both of them are less than $1 \mathrm{~mm}$. At the arch foot of the left tunnel, the construction of the middle drift in the original design scheme will cause compression deformation of about $0.36 \mathrm{~mm}$. The optimization scheme will cause expansion deformation of about $0.21 \mathrm{~mm}$.

(3) After the completion of the construction, the maximum expansion of the original scheme is $0.33 \mathrm{~mm}$ of the arch waist, and the maximum compression is $6.09 \mathrm{~mm}$ of the left tunnel arch foot. The maximum expansion of the optimized scheme is $2.52 \mathrm{~mm}$ of the left tunnel arch waist, and the maximum compression is $5.30 \mathrm{~mm}$ of the right tunnel arch foot. The horizontal convergence trend of the tunnel caused by the two construction schemes is basically the same in the right tunnel. And, the convergence at the arch foot is almost the same. Because the change of construction scheme is mainly in the left tunnel, the deformation curves of the three measuring points are quite different and concentrated after the construction of the left line tunnel.

In summary, the location of the measuring point will cause a sudden change in the clearance convergence when the tunnel is excavated past the monitoring surface. However, this does not affect the tunnel clearance deformation results. The excavation of the middle drift has a slight impact on the clearance deformation of the tunnel, but the main impact comes from the excavation of its own tunnel. It should be noted that the deformation of the arch waist position should be controlled in the optimization scheme.

5.2. Comparative Analysis of Stress of Primary Support Structure. In order to meet the requirements of strength and stability of underground structures, structural design codes similar to the characteristics of underground structures should be selected according to the construction method, structure type, and load characteristics and combined with construction monitoring for information design. Table 2 


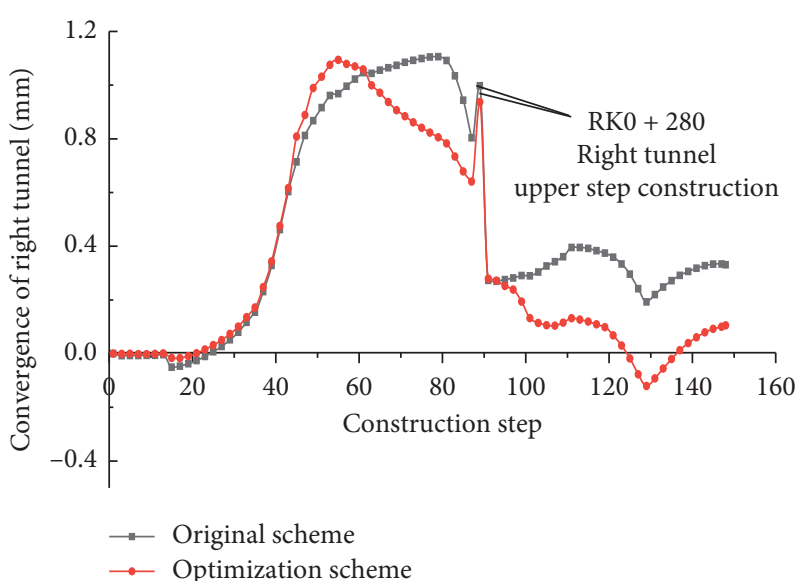

(a)

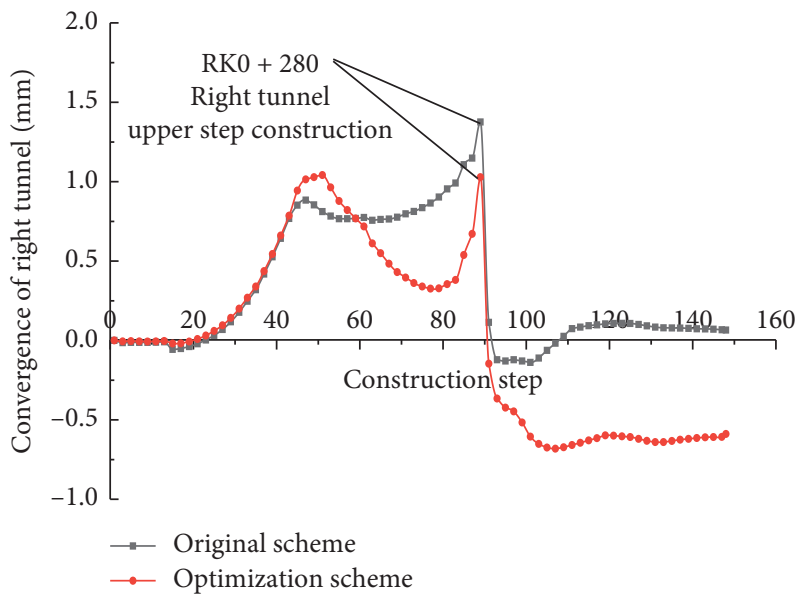

(b)

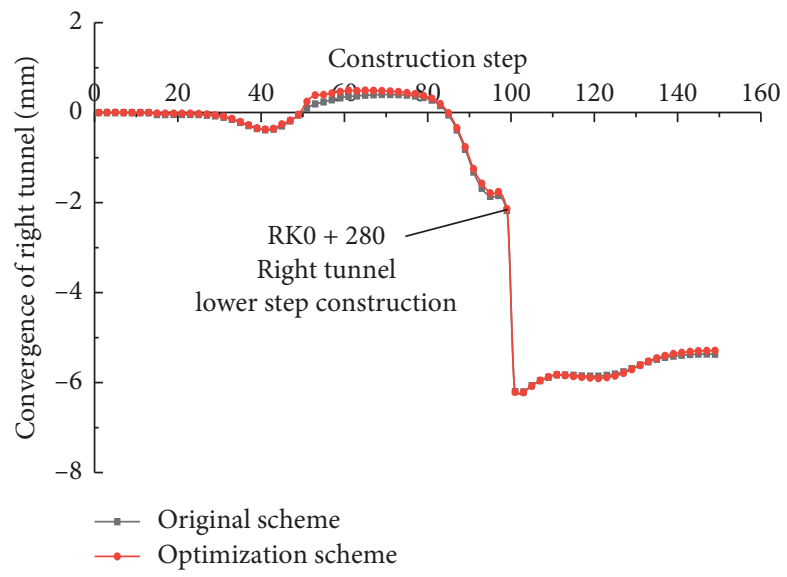

(c)
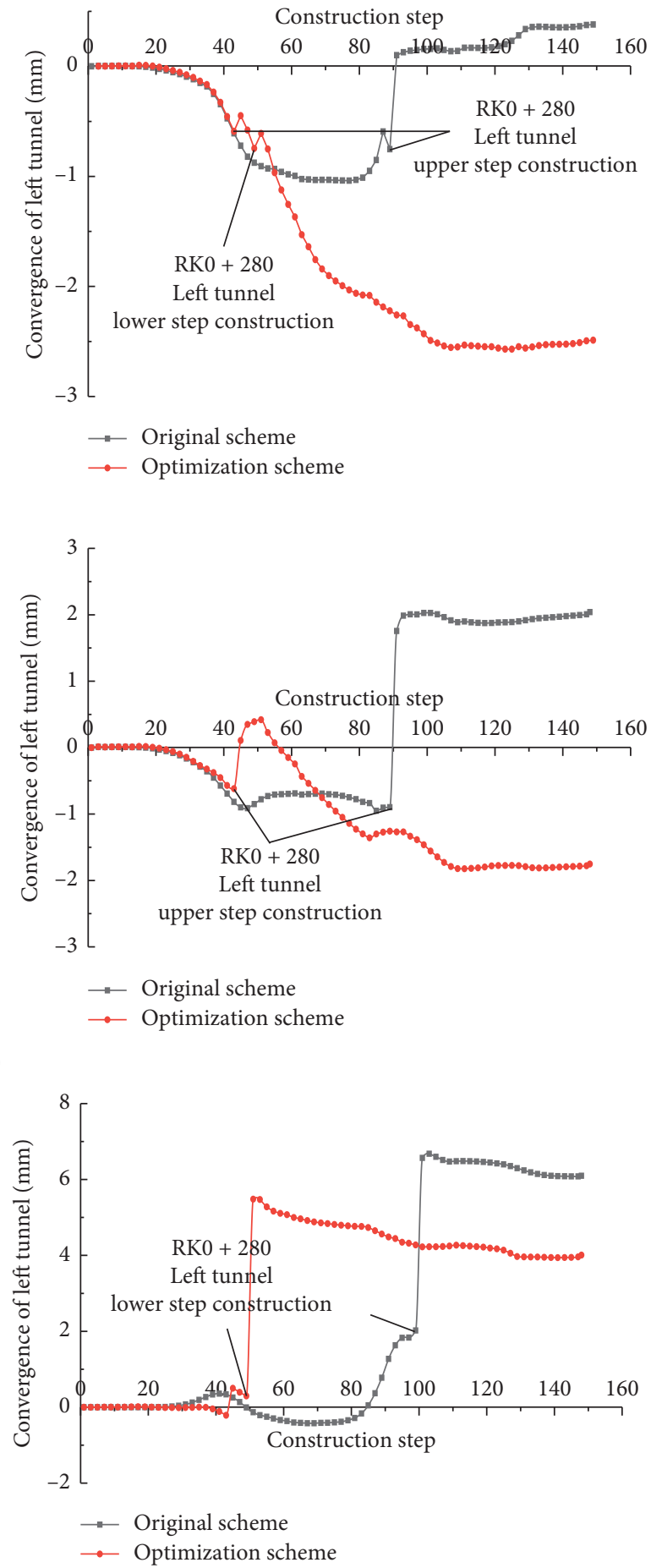

FIGURE 14: Convergence contrastive analysis of the left and right tunnel at RK0 +280 . Convergence deformation of (a) arch waist, (b) spandrel, and (c) arch foot.

TABLE 2: Mechanical properties of shotcrete (MPa).

\begin{tabular}{lcc}
\hline & & Spray mixing strength grade \\
Design strength category & $\mathrm{C} 25$ & C30 \\
\hline Axial compression resistance $(\mathrm{MPa})$ & 12.5 & 15 \\
Bend compression resistance $(\mathrm{MPa})$ & 13.5 & 16.5 \\
Tensile $(\mathrm{MPa})$ & 1.3 & 1.5 \\
\hline
\end{tabular}


shows the strength design values of different grades of concrete applied in railway tunnel design specifications [27].

5.2.1. Comparative Analysis of Initial Support Forces. The peak value and position of the maximum tensile stress are different in different construction schemes. After the completion of the original design and construction, the peak position of the maximum tensile stress of the support structure will remain at the section vault position at the end of the middle drift. However, the optimization scheme appears at the modification of the left tunnel $\mathrm{RK} 0+280$ scheme. There are differences in the peak value of the maximum compressive stress caused by the two construction schemes, but the position of the peak value remains at the vault in the initial stage of the middle drift. Figures 15 and 16 are the comparison of the main stress of the initial support under the two schemes.

In the two construction schemes, the maximum tensile stress of $1496.39 \mathrm{kPa}$ appears at the arch waist of RK0 +280 . In the original construction plan, the tensile stress here was $493.43 \mathrm{kPa}$. In the original scheme, the maximum tensile stress of $1023.43 \mathrm{kPa}$ appears at the vault of the middle tunnel at $\mathrm{RK} 0+270$, and in the optimized scheme, the tensile stress is $957.09 \mathrm{kPa}$.

In the optimization scheme, $1861.04 \mathrm{kPa}$ compressive stress appears at the vault of $\mathrm{RK} 0+280$, which is $1554.81 \mathrm{kPa}$ in the original construction scheme. The original scheme showed a maximum compressive stress of $3215.33 \mathrm{kPa}$ at the entrance arch of the middle drift in the section tunnel, and in the optimized scheme, the compressive stress was $2191.44 \mathrm{kPa}$. According to the comparison of the main stress cloud chart, the construction of the optimization scheme at RK0 +280 of the left tunnel should be taken as the key point of control. The appropriate measures to strengthen the support can be taken to ensure the construction safety. The initial support structure is reinforced concrete structure. When the tensile stress of the support structure meets the mechanical performance index of shotcrete in Table 2, the construction scheme with smaller compressive stress is more reasonable. Based on the stress characteristics of the support structure, the optimization scheme which is more favorable for the supporting structure of the ingate section is better for the double arch tunnel.

\subsection{Comparative Analysis of Stress and Deformation of Shaft and Cross Passage Support Structure}

5.3.1. Comparative Analysis of the Stress of Shaft and Cross Passage Support Structure. In the actual construction process, the support structure is sensitive to the change of the construction excavation scheme. The secondary disturbance during construction has a great influence on the stability of the supporting structure. Therefore, the support structure should avoid disturbance as much as possible in the construction process. The construction of ingate on the west side of the shaft will inevitably cause secondary disturbance to the structure of the shaft in the early stage. It is necessary to

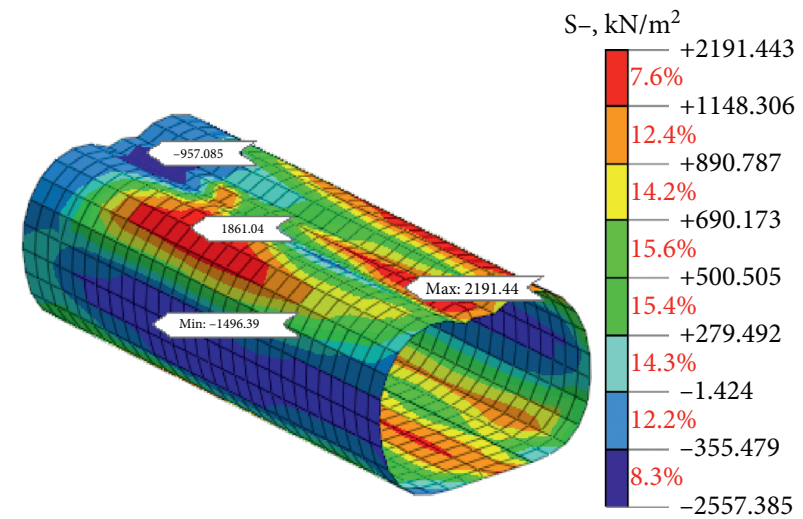

FIGURE 15: Principal stress of initial support in the optimization scheme (unit: $\mathrm{kN} / \mathrm{m}^{2}$ ).

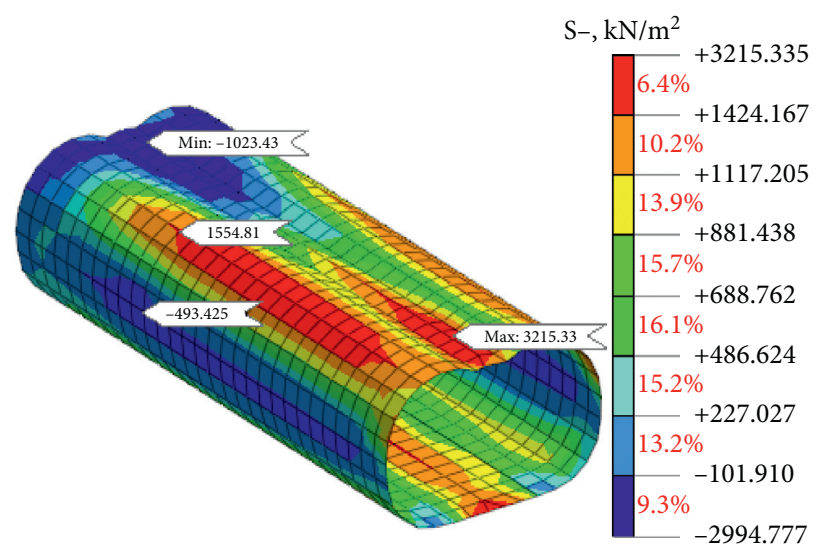

FIGURE 16: Principal stress of initial support in the original scheme (unit: $\mathrm{kN} / \mathrm{m}^{2}$ ).

check the stability of the support structure of the shaft. Figures 17 and 18 are the final stress state comparison of ingate support structure in the west side.

Figures 17 and 18 show the maximum principal stress and the maximum shear stress of the ingate under the two construction schemes. The stress value under the original design scheme is larger than that of the optimization scheme, which is mainly due to the large difference in the construction of the portal section. In the original design and construction scheme, the maximum principal stress appears at the arch bottom of the ingate right tunnel, with a value of 14.10 MPa. In the optimization scheme, the maximum principal stress appears at the arch bottom of the ingate middle tunnel, with a value of $13.61 \mathrm{MPa}$. In the original scheme, the maximum shear stress is $12.02 \mathrm{MPa}$ of the bottom of the left line arch of ingate, and in the optimized scheme, it is $8.95 \mathrm{MPa}$ of the bottom of the right line arch of ingate. In addition, the stress concentration appears at the corner of the support structure. It can be seen from the above that the influence of the construction of the optimized scheme on the supporting structure of the ingate is smaller than that of the original scheme. However, no matter what 


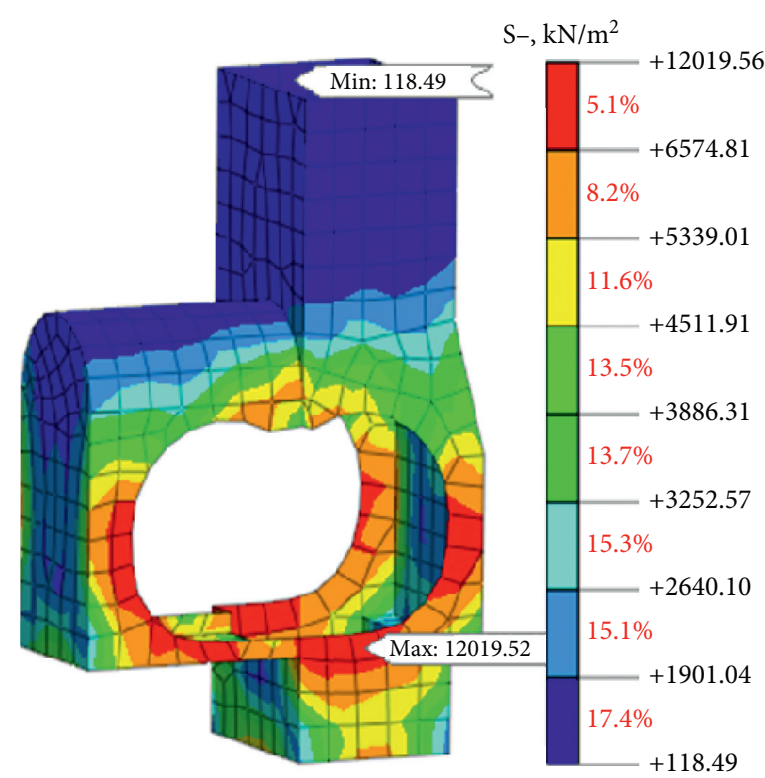

(a)

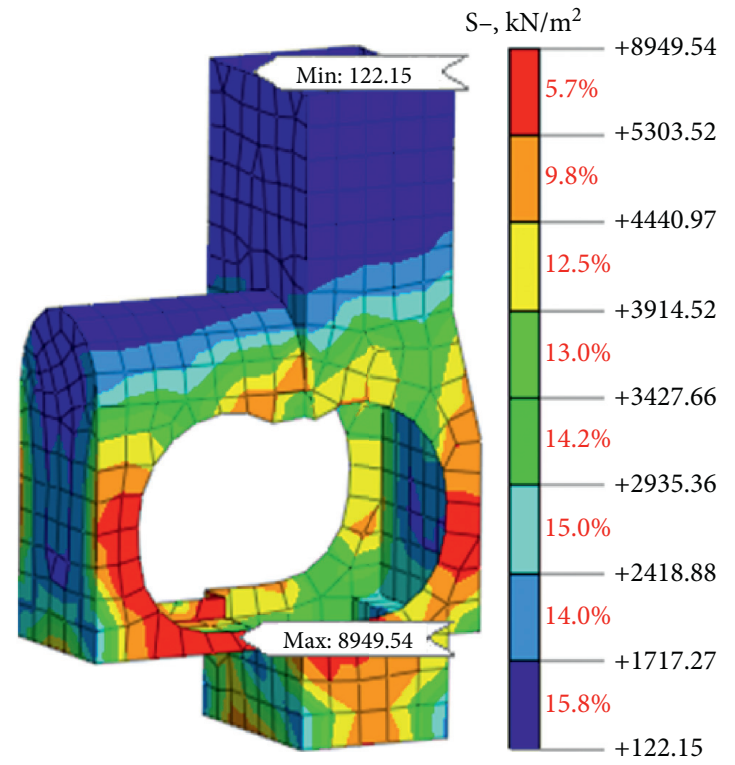

(b)

FIGURE 17: Shear stress distribution of support structure of shaft cross passage (unit: $\mathrm{kN} / \mathrm{m}^{2}$ ): (a) original scheme and (b) optimization schemes.

the construction scheme is, the position of the ingate is the key control position of the construction. Its support strength should be strengthened.

\subsubsection{Comparative Analysis of Deformation of Shaft and} Cross Passage Support Structure. In the excavation process of underground structure, the stability of surrounding rock can directly affect the deformation of support structure. Therefore, different construction schemes at ingate directly lead to different deformation of shaft support structure. For the better scheme, the following is a comparative analysis of shaft support deformation. The deformation comparison curve is shown in Figure 19.

It can be seen from Figure 19(a) that the trend of displacement and deformation curve under the two construction schemes is basically the same. After the deformation is stable, the deformation value of the west ingate under the original scheme is $0.65 \mathrm{~mm}$ larger than that of the optimization scheme. In the original scheme, the impact of breaking the ingate support on the vertical deformation is significantly greater than that of the optimization scheme. This is closely related to the adjustment of the optimization program to the construction process. From Figure 19(b), it can be seen that the vertical deformation trend of ingate arch crown of the tunnel between the two construction schemes is basically the same. The deformation of the original scheme is larger than that of the optimization scheme, and the peak difference of ingate on the west side is $2.2 \mathrm{~mm}$. It can be seen that the optimization scheme is obviously superior to the original design scheme in the optimization of ingate.

\section{Field Monitoring Data Analysis}

In order to ensure the construction safety of the ingate section, the surface settlement and shaft deformation were monitored during the construction. The surface monitoring points of the shaft are shown in Figure 20. After the deformation of the monitoring point is stable, the monitoring data are compared with the numerical simulation results.

In Figure 21, the monitoring and simulation results of surface settlement of DB57 series are compared. As shown in the figure, although the numerical simulation results are smaller than the observation data locally, the observed construction monitoring data are very similar to the simulation analysis results. Due to the influence of shaft and cross passage construction, the maximum settlement observed is about $4 \mathrm{~mm}$, which is obviously less than the allowable control value. The deformation monitoring data and simulation results of the measuring point DB56-5 are shown in Figure 21(b). Within the surface range of ingate, the difference between the peak value of the surface settlement monitoring value and the simulation value is about $2.47 \mathrm{~mm}$, and the deformation trend is similar.

According to the comparative analysis of the above results, there is a certain difference between the monitoring curve of the construction value and the numerical simulation results. Because the numerical model is difficult to simulate the surrounding rock damage caused by construction disturbance, the results obtained are more conservative than the measured values. In most cases, the numerical simulation results are smaller than the on-site monitoring values, but the 


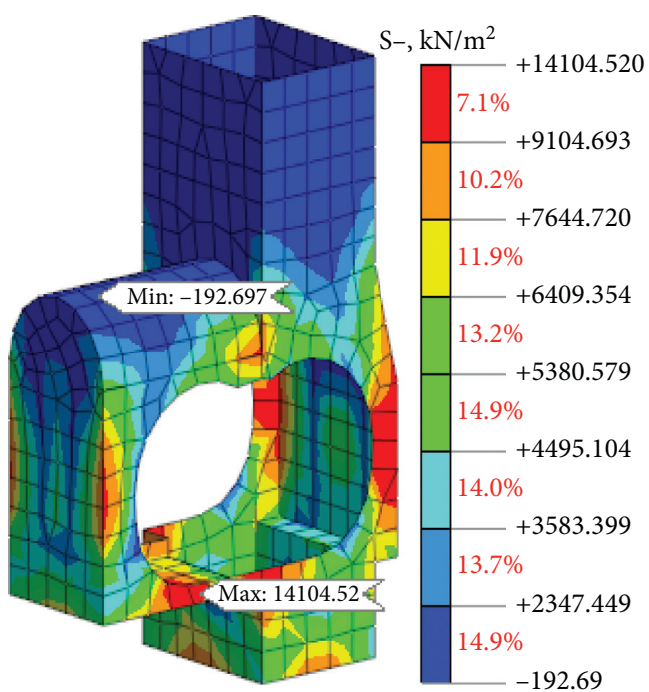

(a)

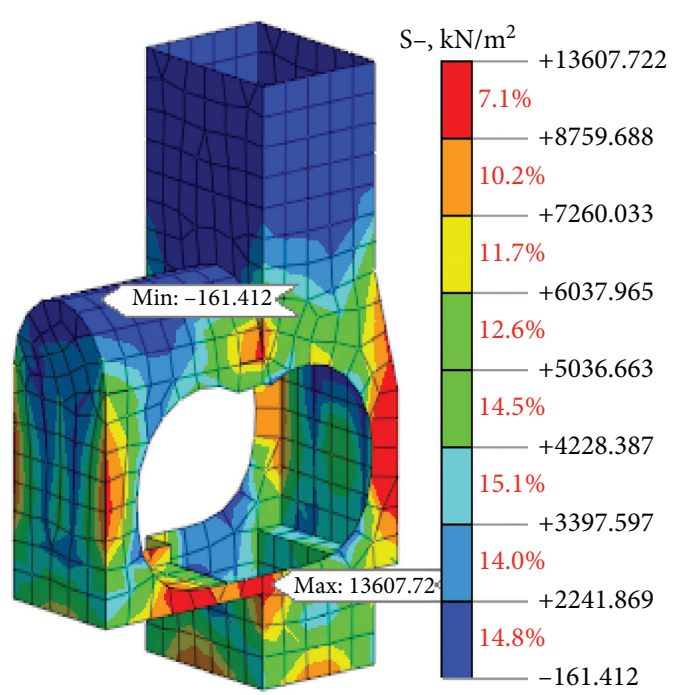

(b)

FIGURE 18: Distribution of main stress in the supporting structure of shaft transverse passage (unit: $\mathrm{kN} / \mathrm{m}^{2}$ ): (a) original scheme and (b) optimization schemes.

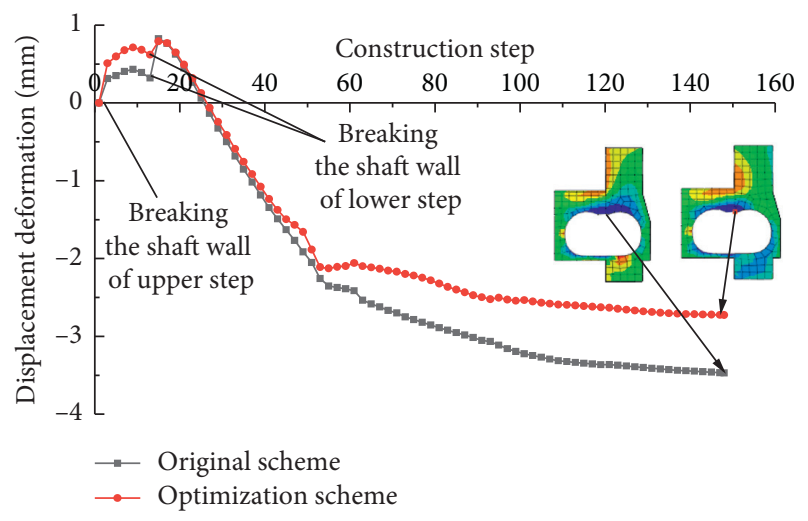

(a)

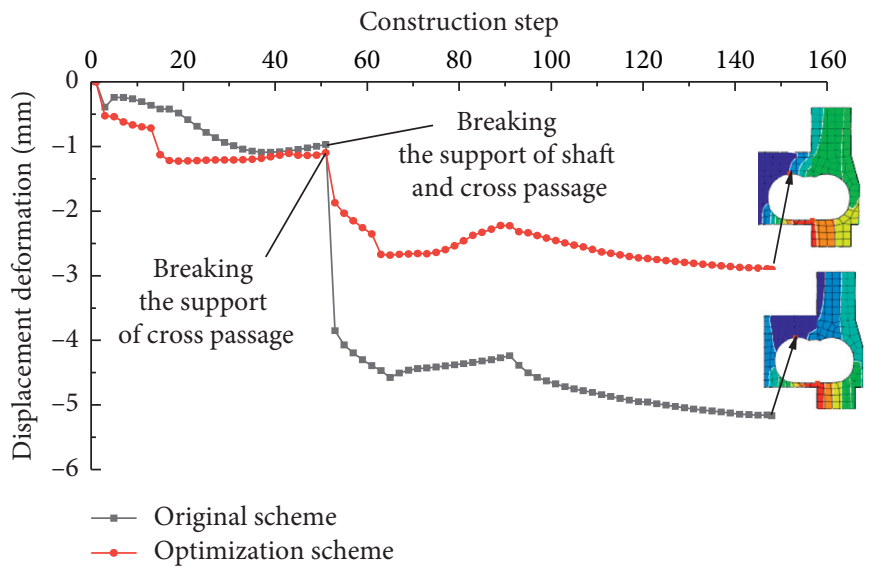

(b)

FIgURE 19: Comparison of displacement and deformation of support structure of cross passage of ingate arch roof: (a) horizontal displacement comparison; (b) vertical displacement comparison.

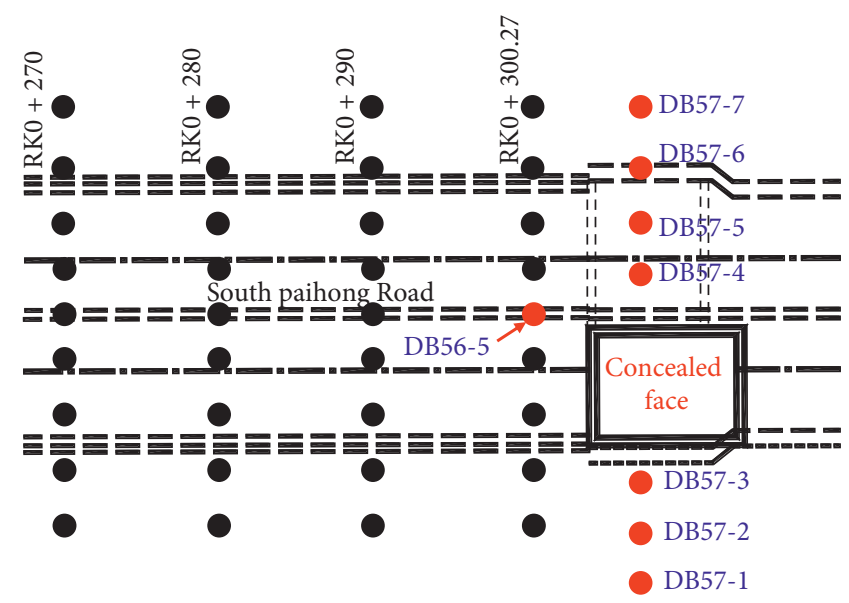

FIgURE 20: Vertical shaft surface monitoring points. 


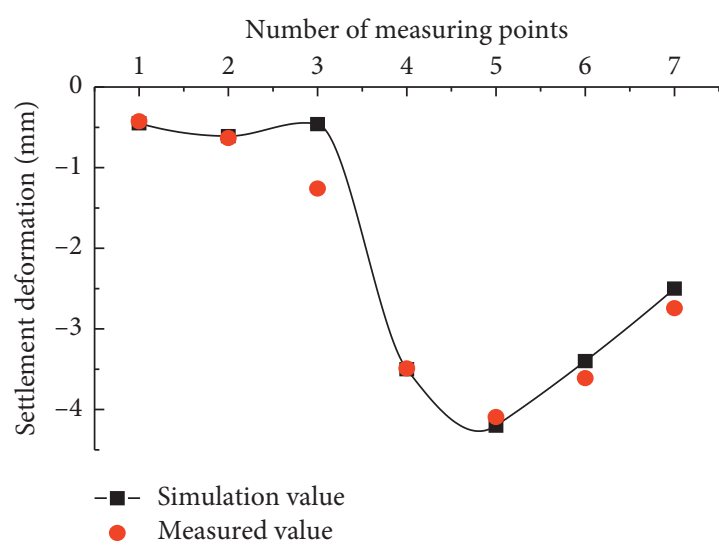

(a)

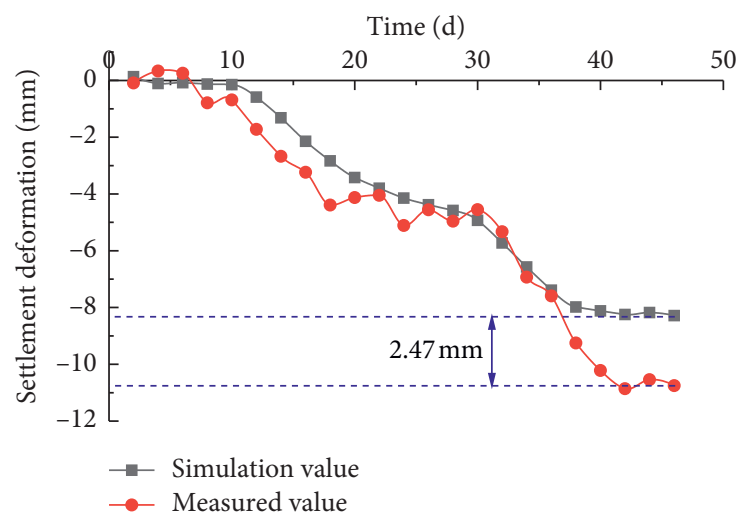

(b)

Figure 21: Vertical shaft surface subsidence monitoring comparison: (a) comparison of DB57 series results; (b) comparison of DB56-5 results.

overall change trend is more consistent. As a whole, the field surface settlement is far less than the surface settlement control value of $40 \mathrm{~mm}$. Therefore, the optimization scheme is technically safe and feasible.

\section{Conclusion}

Based on the analysis of the geological conditions along the Lanzhou metro, the soil layer in the tunnel section is simplified into four layers. In addition, the surface settlement, supporting deformation, and stress of the characteristic section of the tunnel under the two construction schemes are simulated and analyzed by using the finite element method. The optimal scheme and key points of construction control are compared. The specific conclusions are as follows:

(1) Under two different construction schemes, the original design has a great influence on the settlement and deformation of the stratum. In the construction of shafts and cross passage entering the section tunnel with strict requirements for surface settlement control, it is recommended to use the optimization scheme described in this article.

(2) The displacement and stress of the support structure meet the design and specification requirements. In the comparative analysis of the convergence and deformation of the supporting structure at $\mathrm{RK} 0+280$, the deformation trend of the right line tunnel is basically the same. Because the construction plan is mainly changed in the left line tunnel, the deformation curve is greatly different. Combined with the analysis of the supporting structure, the peak tensile stress appears at the RK0 +280 arch waist in the optimized scheme, and the peak compressive stress appears at the $\mathrm{RK} 0+300$ arch crown of the original scheme. In addition, considering the stress characteristics of the concrete supporting structure, the optimization scheme is more appropriate.
(3) Through the stress conversion and deformation analysis of the support structure of the shaft and the cross passage, it can be seen that the connection between the shaft wall and the cross passage support is the position where the shaft support has the largest deformation under the two schemes. Attention should be paid to the joints of the supporting structures of the ingate section, which are the main stress concentration areas. Based on the analysis in section 5.3, the optimization scheme is superior to the original design scheme in the deformation control of key parts such as ingate.

(4) The values of finite element numerical simulation parameters are conservative. The calculation result is slightly larger than the monitoring data, but the overall trend of the value is more consistent with the actual monitoring value.

Although the two schemes have been numerically analyzed and compared in this paper, the nature of the mechanical behavior of the formation and structure has not been deeply analyzed. At present, the physical and mechanical parameters of composite structures are difficult to accurately quantify, and the theoretical analysis of complex spatial structures is difficult to verify. Therefore, it is difficult to guarantee the rigor of the results obtained. In the future, we will focus on the abovementioned problems and strengthen the comparative analysis with on-site measured data.

\section{Data Availability}

The data used to support the findings of this study are included within the article.

\section{Conflicts of Interest}

The authors declare that they have no conflicts of interest. 


\section{Acknowledgments}

The present work was subsidized and supported by the National Natural Science Foundation of China (no. 51578447), the Science and Technology Innovation Team of Shaanxi Innovation Capability Support Plan (no. 2020TD005), the Shaanxi Province Housing Urban and Rural Construction Science and Technology Plan Project (no. 2019-K39), the China Postdoctoral Science Foundation (no. 2018M643809XB), and the Natural Science Basic Research Program of Shaanxi (no. 2019JQ762). The financial support is gratefully acknowledged by the authors.

\section{References}

[1] Z. Song, X. Tian, G. Zhou, and W. Li, "Theoretical analysis of the mechanical behavior of pre-supporting pipe shed in tunnel," China Journal of Highway and Transport, vol. 33, no. 4, pp. 89-98, 2020.

[2] D. Wang, H. Qu, and W. Li, "Issues affecting ground subsidence induced by covered excavation for large crosssectional twin tunnel under existing structures," Chinese Journal of Rock Mechanics and Engineering, vol. 33, no. S2, pp. 40754085, 2014.

[3] J. X. Lai, J. Qiu, H. Fan et al., "Structural safety assessment of existing multiarch tunnel: a case study," Advances in Materials Science and Engineering, vol. 2017, Article ID 1697041, 11 pages, 2017.

[4] S. Fan, Z. Song, Y. Zhang, and N. Liu, "Case study of the effect of rainfall infiltration on a tunnel underlying the roadbed slope with weak," Inter-Layer, vol. 24, no. 2, pp. 1607-1619, 2020.

[5] J. Lai, H. Fan, B. Liu, and T. Liu, "Analysis of seismic response of shallow large section multi-arch tunnel," Procedia Engineering, vol. 15, pp. 5473-5477, 2011.

[6] Y. Li, X. Jin, Z. Lv, J. Dong, and J. Guo, "Deformation and mechanical characteristics of tunnel lining in tunnel intersection between subway station tunnel and construction tunnel," Tunnelling and Underground Space Technology, vol. 56, pp. 22-33, 2016.

[7] Y.-D. Huang, X.-L. Gong, Y.-J. Peng, and C.-N. Kim, "Effects of the solid curtains on natural ventilation performance in a subway tunnel," Tunnelling and Underground Space Technology, vol. 38, pp. 526-533, 2013.

[8] M. Afifipour, M. Sharifzadeh, K. Shahriar, and H. Jamshidi, "Interaction of twin tunnels and shallow foundation at Zand underpass, Shiraz metro, Iran," Tunnelling and Underground Space Technology, vol. 26, no. 2, pp. 356-363, 2011.

[9] N.-A. Do, D. Dias, P. Oreste, and I. Djeran-Maigre, "Threedimensional numerical simulation of a mechanized twin tunnels in soft ground," Tunnelling and Underground Space Technology, vol. 42, pp. 40-51, 2014.

[10] H. Gerçek, "Stability considerations for underground excavation intersections," Mining Science and Technology, vol. 4, no. 1, pp. 49-57, 1986.

[11] L. L. Guan, S. H. Baldauf, and W.-P. N. Chen, "Three dimensional simulation of progressive tunneling process for lining design of intersecting tunnels in soft rock," in Computing in Civil Engineering, ASCE, Reston, VA, USA, 1994.

[12] Y. Cheng, Z. Song, J. Jin, T. Wang, and T. Yang, "Waveform characterization and energy dissipation of stress wave in sandstone based on modified SHPB tests," Geomechanics and Engineering, vol. 22, no. 2, pp. 187-196, 2020.
[13] R. Han and Y. Xie, "Rational transformation of structural stress in shallow buried excavation," Modern Tunnel Technology, vol. 71, no. 03, 2007.

[14] X. Tian, Z. Song, and Y. Zhang, "Monitoring and Reinforcement of landslide induced by tunnel excavation: a case study from Xiamaixi tunnel," Tunnelling and Underground Space Technology, In Press.

[15] B. Guo, "Comprehensive construction technology of ingate project of Beijing subway tunnel," Tunnel Construction, vol. 32, no. 02 , p. 201, 2012.

[16] M. Bai and X. Ji, "Numerical simulation analysis of largespan tunnel under the construction of small vertical shaft crossing passage," Journal of Underground Space and Engineering, vol. 11, no. 02, p. 469, 2015.

[17] C. Song, H. Ji, Y. Zhang et al., "Influence of principal stress on stability of surrounding rock of ingate in weakly consolidated soft rock," Journal of Mining and Safety Engineering, vol. 33, no. 06, p. 965, 2016.

[18] Q. Jiang, X. Huang, K. Zhou et al., "Construction technology and monitoring analysis of subway tunnel ingate under complex condition," Chinese Journal of Rock Mechanics and Engineering, vol. 29, no. S1, pp. 2858-2865, 2010.

[19] Z. Song, Z. Cao, J. Wang et al., "Optimal analysis of tunnel construction methods through cross passage from subway shaft," Advanced in Civil Engineering, vol. 2018, no. 44, p. 173, 2018.

[20] W. Mao, shunchuan Wu, Y. Gao, L. Ge, and X. Li, "Study on construction monitoring and numerical simulation of double arch tunnel," Geotechnical Mechanics, vol. 32, no. 12, pp. 3787-3795, 2011.

[21] Q. Liao, T. Li, R. Li et al., "Analysis of support and excavation methods of ingate in miscellaneous filled soil layer of underground tunnel," Chinese Journal of Engineering Geology, vol. 24, no. 04, p. 668, 2016.

[22] L. Han, "Safety control technology for construction of metro vertical shaft and transverse passage into largesection main line tunnel," Railway Energy Conservation, Environmental Protection and Safety and Health, vol. 6, no. 05, p. 251, 2016.

[23] heng Wang, "Analysis and measures of construction settlement by shallow buried excavation method," Engineering Construction and Design, vol. 10, p. 194, 2019.

[24] Bo Wu, W. Liu, Bo Gao, X. Suo, and Y. Shi, "Three-dimensional numerical simulation and analysis of the construction behavior of a subway bifurcated tunnel," Chinese Journal of Rock Mechanics and Engineering, vol. 18, pp. 3081-3086, 2004.

[25] Z. Song, X. Tian, L. Qi et al., "Numerical analysis and application of the construction method for the small interval tunnel in the turn line of metro," Science Progress, vol. 103, no. 3, 2020.

[26] X. Tian, Z. Song, G. Zhou, and X. Zhang, "A theoretical calculation method of the unsupported span for the shallow tunnel in the soft stratum," Advances in Civil Engineering, vol. 2020, Article ID 7989036, 11 pages, 2020.

[27] China Railway Publishing House, Railway Tunnel Design specifications: TB 100032016, China Railway Publishing House, Beijing: China, 2016. 